\title{
Fenomenologia do Tempo Vivido no Transtorno Bipolar
}

\author{
Virginia Moreira $^{1}$ \\ Lucas Bloc \\ Universidade de Fortaleza
}

\begin{abstract}
RESUMO - Com base na tradição da psicopatologia fenomenológica, este artigo se propõe a contribuir para a compreensão do mundo vivido do paciente bipolar, marcado por uma forte alteração do tempo vivido. Realizamos uma descrição deste tempo vivido significado de forma diferente nas oscilações de humor chamadas de fase maníaca e fase melancólica. Pensado a partir da temporalidade, na fase melancólica, o bipolar parece parar no tempo, não se lança em um devir. Na fase maníaca, o sujeito vive demasiadamente um agora como se tivesse explodido sua biografia. Concluímos que estas fases, ou dois pólos opostos no funcionamento temporal patológico do sofrimento bipolar, constituem fundamentalmente um mesmo mundo vivido.
\end{abstract}

Palavras-chave: transtorno bipolar; tempo vivido; psicopatologia fenomenológica.

\section{Phenomenology of Experienced Time in a Bipolar Disorder}

\begin{abstract}
Based on the phenomenological tradition of psychopathology, this article aims to contribute to the comprehension of the world as experienced by bipolar patients, which is characterized by a strong shift in the experience of time. A different description of the experienced time was made for the manic and depressive phase. During a depressive phase the bipolar patient seems to stop in time. In the manic phase, the subject lives completely focused on the here and now, as if his there has been no life before the present. We conclude that these phases, or the two opposite poles in the pathologic operation of time of bipolar suffering, are fundamentally part of the same experienced world of bipolar patiens.
\end{abstract}

Keywords: bipolar disorder; lived time; phenomenological psychopathology.

O transtorno bipolar é uma doença crônica e complexa, caracterizada por sua grande mutabilidade, pelas formas diferentes de manifestação e por sua instabilidade; característica marcante e manifestada através de sintomas flutuantes e muitas vezes inversos (Tung, 2007), abrangendo os extremos da experiência humana. A conceituação do transtorno bipolar, mesmo utilizando outras nomenclaturas, é tão antiga quanto a própria medicina, apresentando-se de forma consistente e uniforme, apesar das mudanças históricas na sua delimitação e definição (Goodwin \& Jamison, 2010).

Neste artigo utilizamos a denominação transtorno bipolar ou bipolaridade, mas existem outros termos utilizados, tais como transtorno afetivo bipolar e transtorno bipolar do humor, considerado atualmente o mais correto (Silva \& Cordás, 2006; Tung, 2007). Tais denominações fazem referência à sua classificação em termos psiquiátricos e à utilização dos termos afeto e humor. Afetos fazem referência a emoções que surgem mais rapidamente a partir de uma situação de vida imediata. Já humores são referentes a estados mais prolongados, durando horas, dias ou semanas, chegando a influenciar a forma de pensar e agir de uma pessoa (Tung, 2007).

As oscilações de humor são muito presentes na estruturação da nossa vida cotidiana. No entanto, uma oscilação

1 Endereço para correspondência: Universidade de Fortaleza - UNIFOR, Programa de Pós-Graduação em Psicologia, APHETO - Laboratório de Psicopatologia e Psicoterapia Humanista Fenomenológica Crítica. Av. Washington Soares, 1321. Fortaleza, CE. CEP 60811-341. E-mail: virginiamoreira@unifor.br. extrema e sem claros determinantes lógicos ou causais acaba por ultrapassar a barreira daquilo considerado normal. Há um limiar tênue entre aquilo considerado normal e o considerado patológico, embora muitas vezes possam existir traços dessas ou daquelas psicopatologias nas diversas manifestações humanas. Pensamos a saúde psicológica como um movimento de construção existencial cotidiana e a patologia como uma imobilização do ser, uma cristalização, uma existência cotidiana doente, sendo o sofrimento a única alternativa (Moreira, 2001, 2009). Tal descrição nos permite situar uma marca diferencial daquilo que seria o normal e o patológico dentro da perspectiva da psicopatologia fenomenológica, referencial utilizado neste artigo.

Segundo Binswanger (1960/2005), melancolia e mania são as duas fases clínicas manifestas, da chamada na época, doença maníaco-depressiva e hoje denominado de Transtorno Bipolar. Ele defende o estudo dos momentos constitutivos estruturais do mundo melancólico e do mundo maníaco, bem como suas diferenças.

Este artigo se propõe a compreender o mundo vivido bipolar, utilizando a perspectiva da psicopatologia fenomenológica. Focalizamos a temporalidade enquanto categoria fenomenológica, uma das bases estruturantes da condição de ser sujeito e constitutiva da gênese deste fenômeno marcado por uma alternância, sem determinantes temporais, de extremos que, mesmo polares, possuem uma forte ligação. Descrevemos separadamente estas duas fases extremas apenas para efeitos didáticos, buscando compreender, a partir da temporalidade, a experiência vivida de pessoas com tal doença. 
Neste artigo realizamos uma breve revisão histórica das manifestações desta psicopatologia, bem como sua evolução. Discutimos o diagnóstico do transtorno bipolar na atualidade, trazendo dados epidemiológicos e discorremos sobre o tempo vivido, dando subsídios para refletir sobre a temporalidade na melancolia e na mania. Finalmente, discutimos sobre o tempo vivido bipolar, pensando fenomenologicamente esta forma de existir no mundo.

\section{Breve histórico}

Depressão, melancolia, mania são termos recorrentes na configuração do transtorno bipolar. Estudos apontam que historicamente tais termos e formas de existir no mundo sempre estiveram presentes (Alcantara et al., 2003; Goodwin \& Jamison, 2010; Moreira, 2002; Tatossian, 1979/2006; Widlöcher, 1995/2001). Até chegar na denominação contemporânea de Transtorno Bipolar, um grande caminho foi percorrido. Os primeiros escritos que relatam a existência da melancolia datam da civilização Greco-romana e são descritos em personagens bíblicos como o Rei Saul, no antigo testamento e personagens mitológicos, como Homero, na Ilíada. Os escritos naturalistas de Hipócrates, datados do século IV e V a.C. já descreviam a melancolia de forma puramente biológica, forma que perdurou até o Renascimento e marcou uma substituição da magia pela biologia (Alcantara et al., 2003).

Até o início da Idade Média, os médicos eram quem tratavam os problemas físicos e mentais. Com o fortalecimento da igreja, a doença mental passou a ser atribuída à magia, ao pecado e à possessão demoníaca; um alvo da Santa Inquisição. No final da Idade Média e com a ascensão das ciências empíricas, houve maior interesse e aceitação (Alcantara et al., 2003).

Pinel, em 1809, caracterizou a melancolia e a mania. Já Esquirol, discípulo de Pinel, reconheceu o transtorno afetivo como uma forma diferente de perturbação mental, chamada por ele de "lypemanie" e abandonou o termo melancolia. Com ele, ocorreu um distanciamento do conceito de loucura global e uma aproximação do conceito de loucura parcial, oriunda primariamente das emoções. Somente com a aproximação da descrição psicopatológica da depressão foi que o conceito anterior de melancolia pôde ser reconhecido como integrante da doença maníaco-depressiva (Alcantara et al., 2003).

As primeiras concepções explícitas da doença maníaco-depressiva como entidade nosológica única foram elaboradas na metade do século XIX por Jules Falret e J. F. Baillarger. O trabalho de Kraepelin também foi fundamental, agrupando todas as psicoses em uma entidade fundamental e considerando a doença maníaco-depressiva como uma afecção endógena e constitucional. O ano de 1966 foi marcado pelo renascimento da doença bipolar, com publicações marcantes de Jules Angst e Carlo Perris. Já em 1976, introduziu-se a distinção entre Bipolar tipo 1 (com episódios maníacos) e Bipolar tipo 2 (com episódios hipomaníacos). Desde então, a discussão tem se ampliado ainda mais, estendendo-se até o espectro bipolar, discutido nos dias de hoje (Alcantara et al., 2003; Goodwin \& Jamison, 2010).

\section{O diagnóstico do transtorno bipolar na atualidade}

Os critérios diagnósticos são fundamentais e os mais utilizados são o da Organização Mundial de Saúde e o DSM-IV. Suas classificações são pensadas em termos de "episódio" atual ou recorrente, que é definido como "fase da vida do indivíduo marcada por sintomas afetivos" (Tung, 2007, p. 57), podendo durar dias ou anos. Existem quatro tipos diferentes de episódios, definidos como: depressivo, hipomaníaco, maníaco e misto. Podemos observar que a definição é dada com base nos tipos de episódios que uma pessoa tem, mas na prática estes não são fáceis de serem percebidos. Um agravante se dá quando se trata da diferenciação da depressão unipolar em relação à depressão bipolar, pois, em muitos casos, pessoas passam anos sem apresentar nenhum episódio maníaco e quando passam a manifestar tal quadro, o diagnóstico muda para transtorno bipolar. Tal dificuldade prejudica bastante o tratamento e também gera dificuldade para a mensuração epidemiológica (Tung, 2007).

Para o diagnóstico, a forma de apresentação clínica e os pontos essenciais de anamnese são fundamentais. O humor, o ânimo e a disposição do paciente são importantes na anamnese. Uma pessoa na fase depressiva costuma apresentar apatia, falta de cuidado com a aparência ou mesmo com a higiene, falta de interesse pelos acontecimentos que o cercam e frequente fadiga ou cansaço. Questionamentos sobre concentração e memória são importantes. A auto-estima e a autoconfiança ficam abaladas, além de possíveis idéias de culpa, pessimismo e falta de perspectiva de futuro. Frequentemente os pacientes possuem insônia ou uma sensação de cansaço e sonolência, podendo levar a comportamentos e idéias suicidas (Silva \& Cordás, 2006).

$\mathrm{Na}$ fase maníaca, o indivíduo apresenta características provenientes do humor elevado - agitação, verborréia (muito falante), hipervigilância (atenção a tudo) e se mostra hipotenaz (sem concentração em um foco de atenção). $\mathrm{O}$ indivíduo costuma saltar de assunto em assunto, aumentar exageradamente a auto-estima, expressar-se com eloquência e manifestar ideias de grandeza. Em quadros graves, o paciente pode apresentar sintomas psicóticos como ideias delirantes, alucinações auditivas ou extrema agitação psicomotora (Silva \& Cordás, 2006).

Segundo a CID-10 (Organização Mundial de Saúde [OMS], 1993), o transtorno afetivo bipolar se enquadra entre os transtornos do humor (afetivos). No entanto, a incompreensão da relação entre etiologia, sintomas, processos bioquímicos, resposta ao tratamento e evolução impossibilitam uma aprovação universal. Então, trata-se de uma tentativa de classificação. A perturbação fundamental é uma alteração do humor ou afeto. O transtorno afetivo bipolar, como é chamado nesta classificação, é caracterizado por episódios repetidos, ou seja, pelo menos dois, em que o humor e os níveis de atividade do paciente estão significativamente perturbados. Tais alterações consistem em algumas ocasiões de uma elevação do humor e aumento de energia e atividade (mania ou hipomania) e em outras de um rebaixamento do humor e diminuição de energia (depressão). A recuperação entre episódios é, geralmente, completa e a incidência em ambos os sexos é mais semelhante se comparado a outros transtornos do 
humor. Pacientes com apenas episódios maníacos são raros, pois, usualmente, começam abruptamente e possuem uma duração entre duas semanas e 4-5 meses. Já as depressões tendem a durar mais tempo, algo em torno de seis meses; raramente por mais de um ano, exceto em idosos.

Eventos estressantes da vida ou certos traumas mentais podem ser seguidos por episódios maníacos ou depressivos, mas tais situações não são condições para o diagnóstico. $\mathrm{O}$ primeiro episódio pode ocorrer em qualquer idade e a frequência de episódios e o padrão de remissões e recaídas é bastante variável, muito embora as remissões, com o passar do tempo, tendam a tornarem-se mais breves e as depressões a serem mais comuns e com maior duração depois da meia-idade (OMS, 1993).

Na classificação da CID-10, o transtorno bipolar é classificado em nove formas diferentes, seguindo determinadas diretrizes diagnósticas; são elas: F31.0 - Transtorno afetivo bipolar, episódio atual hipomaníaco; F31.1 - Transtorno afetivo bipolar, episódio atual maníaco sem sintomas psicóticos; F31.2 - Transtorno afetivo bipolar, episódio atual maníaco com sintomas psicóticos; F31.3 - Transtorno afetivo bipolar, episódio atual depressivo leve ou moderado; F31.4 - Transtorno afetivo bipolar, episódio atual depressivo grave sem sintomas psicóticos; F31.5 - Transtorno afetivo bipolar, episódio atual depressivo grave com sintomas psicóticos; F31.6 - Transtorno afetivo bipolar, episódio atual misto; F31.7 - Transtorno afetivo bipolar, atualmente em remissão; F31.8 - Outros transtornos bipolares e T31.9 Transtorno afetivo bipolar, não especificado (OMS, 1993). Como podemos observar, trata-se de uma classificação por episódios dentro da classificação mais geral; transtorno afetivo bipolar (F31).

O DSM IV (American Psychiatric Association [APA], 2002) denomina de transtornos bipolares aqueles tipos de transtorno de humor que envolvem a presença de episódios maníacos, hipomaníacos ou mistos, usualmente acompanhados de episódios depressivos maiores. Segundo esta classificação existem os seguintes tipos de transtornos bipolares: Transtorno Bipolar I, Transtorno Bipolar II, Ciclotimia e Transtorno Bipolar Sem Outra Especificação. A presença de um ou mais episódios maníacos ou hipomaníacos é o que pauta o diagnóstico entre Transtorno Bipolar I ou II, respectivamente.

O termo "Espectro bipolar" tem ganhado espaço e se refere a toda a gama de apresentações clínicas diferentes, indo de um pólo a outro, da depressão unipolar pura, passando pela depressão com poucas hipomanias, depressão com manias ou mesmo as manias puras. Esta forma de pensar a bipolaridade também é oriunda de uma crítica aos modelos de classificação tradicionais (CID-10 e DSM IV). A idéia de espectro repercute principalmente em termos epidemiológicos, acentuando bastante os índices (Tung, 2007). Por se tratar de uma doença da instabilidade, sua classificação é complexa e confusa. Sua maior sistematização é feita através da definição das crises, fases ou episódios de humor, abrindo espaço para a definição de um quadro característico. E nestes termos ele pode ser considerado uma doença depressiva, pois é neste estado que a maioria dos pacientes passa a vida (Tung, 2007).

\section{Epidemiologia}

Segundo Magalhães e Pinheiro (2009), o transtorno bipolar representa um grande desafio para a psiquiatria e áreas fins no sentido de sua detecção, tratamento e detecção de incapacidade, representado na dificuldade de validação dos parâmetros epidemiológicos. Os autores apontam a National Comorbidity Survey (NCS-R) como a melhor estimativa. Seus índices são de $1 \%$ para o transtorno bipolar I; $1,1 \%$ para o transtorno bipolar II e 2,4\% para subliminares. Já o DSM IV aponta o índice de 1,6\% em pacientes com transtorno bipolar I, diminuindo para $0,5 \%$ em pacientes do tipo II (APA, 2002).

Outros estudos também apontam que $1 \%$ da população sofre com tal transtorno (Goodwin \& Jamison, 2010; Lima, Tassi, Novo, \& Mari, 2005; Thobaben \& Wehr, 2004). No entanto, se for pensado em termos de espectro bipolar, tal índice de prevalência na população em geral poderá variar de 3 a 8,3\%. Há uma estimativa da OMS que o transtorno bipolar está entre os dez maiores transtornos incapacitadores em países desenvolvidos (Goodwin \& Jamison, 2010).

Uma pesquisa realizada no Brasil aponta um risco de $18 \%$ de a população ter alguma forma de transtorno afetivo que requeira tratamento alguma vez na vida. Há uma estimativa que, no Brasil, neste momento, $5 \%$ da população apresentaria um quadro depressivo. A depressão está entre as dez doenças mais influentes na má qualidade de vida da população (Tung, 2007). Em termos de gênero, os estudos epidemiológicos apontam igual prevalência entre homens e mulheres (Silva \& Cordás, 2006).

\section{Transtorno bipolar: uma compreensão a partir do tempo vivido}

\section{O tempo vivido na psicopatologia fenomenológica}

A temporalidade é reconhecida por autores da psicopatologia fenomenológica, como Tatossian (1997, 1979/2006), Minkowski (1933/1995) e Binswanger (1960/2005), como um elemento fundamental da gênese do transtorno bipolar. Então, para pensarmos o sofrimento do paciente bipolar, necessariamente devemos compreender seu mundo vivido e as relações que ele estabelece com o tempo.

Segundo Minkowski (1933/1995), uma psicopatologia não pode ser definida por uma associação de sintomas, mas como uma modificação profunda e característica de toda a personalidade. Para ele, toda significação está intimamente ligada ao tempo e ao espaço vivido. No caso específico do transtorno bipolar, há uma modificação das significações relacionadas à temporalidade. Então, para pensarmos o sofrimento, devemos compreender as significações do sujeito bipolar com o tempo, estabelecendo sua perspectiva sobre o vivido.

A temporalidade é uma categoria fenomenológica e uma das bases estruturantes da condição de ser sujeito. Segundo Minkowski (1933/1995), em psicologia e psicopatologia a questão do tempo deve ser pensada em três diferentes aspectos: há o tempo da física e da memória, marcado nos estudos pela desorientação no tempo; o tempo e espaço que 
é representado pela duração mensurável; e aquele em que há somente o tempo, a duração vivenciada, o tempo-qualidade. O tempo pensado como vivido é constitutivo e não reflexivamente pensado. É este tempo-qualidade que buscamos compreender em sua relação com o transtorno bipolar e todo o sofrimento trazido por uma falta de desdobramento no tempo, característica desta psicopatologia. Minkowski (1933/1995) vê o fenômeno do tempo como uma espécie de caleidoscópio, refletindo diante dos olhos a cada instante, sem relaxar, e mostrando imagens novas seja do mundo exterior seja da vida íntima.

Trata-se, segundo Strauss (1968/2000), de um tempo existencial que "não pode ser separado da vida e da história de cada indivíduo; a relação presente-passado-futuro não pode ser reduzida ao esquema mais cedo - mais tarde; o tempo da existência é finito (...) o tempo da existência não pode ser quantificado" (p. 116). Quando nos referimos ao tempo vivido e experienciado, não podemos reduzi-lo ao tempo físico; é necessário reconhecer sua ambiguidade inerente (Strauss, 1968/2000).

Neste artigo, discutimos a perspectiva do tempo vivido trazido por Binswanger (1960/2005) especificamente em seu livro Melancolie e Manie onde ele se desloca de uma ênfase descritiva para uma genética, tendo a historicidade como traço marcante da "passagem do tempo constituído ao tempo constituinte" (Tatossian, 1979/2006, p. 34). Na busca pela constituição do mundo melancólico e do mundo maníaco e tendo como referencial filosófico o último Husserl, nesta obra Binswanger (1960/2005) coloca que o futuro, o passado e o presente são os momentos estruturais intencionais constitutivos dos objetos temporais e os denomina, respectivamente, como protentio (protensão), retentio (retenção) e präsentatio (apresentação). Estes são elementos indissociáveis e que, em condições normais, se intrincam entre si. Então, por exemplo, no ato de falar existe uma apresentação, mas também já existem protensões, se não seria impossível terminar a frase. Ao mesmo tempo, é necessário dispor de retenções para elaborar a frase, caso contrário não se saberia a propósito de que se estaria falando. Para Binswanger (1960/2005), pensar a melancolia e a mania significa descobrir os modos deficientes dessas três dimensões e suas interações. É neste nível de estrutura temporal fundamental que se busca a gênese das alterações do tempo vivido e que Binswanger (1960/2005) buscou desenvolver.

\section{Da melancolia à depressão no transtorno bipolar}

Quando Tatossian (1979/2006) aborda a melancolia e a depressão, observamos uma divisão muito tênue daquilo que seria um ou o outro fenômeno psicopatológico. Nesse sentido, consideramos importante fazer uma breve diferenciação e pensar como tais formas de existir aparecem ou não no mundo vivido bipolar. Além disso, é importante situarmos o que Tatossian (1979/2006) chama de experiência da depressividade.

Binswanger (1960/2005) evita utilizar a palavra depressão, argumentando que esta possui significados variados e não serviria como ponto de partida para uma análise fenomenológica. Ele cita algumas formas de depressão como: depressão endógeno-reativa, depressão vital, vegetativa, hipocondríaca, existencial, entre outros.

$\mathrm{Na}$ depressão há uma espécie de identificação com a tristeza e o viver passa a não ter mais sentido; o sujeito se sente despotencializado (Moreira, 2002, 2009) e, ao mesmo tempo, identificado, preso ao sentimento que lhe traz sofrimento - uma tristeza vital. Há uma incapacidade de sentir atrelada amplamente àquilo vivido no passado (Tatossian, 1979/2006).

Na melancolia há uma reação ao ser, não havendo uma identificação com a tristeza, a reação do paciente é reação àquilo que está acontecendo. A tristeza do melancólico é por não poder ser, não poder viver aquilo que gostaria na sua existência, ficando preso a papéis sociais (Bin, 1998; Tatossian, 1979/2006). O melancólico está preso às experiências já tidas, sendo insuportável a surpresa, pois ele vive preso a um "passado que não pode, portanto, se dissipar e se faz sempre mais pesado e determinante" (Tatossian, 1979/2006, p. 137). Ele pode se dizer triste, mas é uma tristeza reacional ao seu vivido nuclear.

$\mathrm{Na}$ depressão, o sofrimento se situa no campo do sentimento, enquanto que na melancolia trata-se de uma questão de humor. Um humor enraizado na totalidade do sujeito, subtraído à sua vontade e que demarca um fundo global único a cada momento, enquanto vários sentimentos podem coexistir. $\mathrm{O}$ sentimento faz referência àquilo que o indivíduo era ou possuía e suas significações e, diferentemente do humor, permite mais facilmente uma compreensão psicológica (Tatossian, 1979/2006). Então, em termos de sintomatologia há uma proximidade, mas em termos fenomenológicos há uma clara e necessária distinção.

Consideramos que aquilo chamado por Tatossian (1979/2006) de melancolia está mais próximo das características da fase depressiva do bipolar, embora seja possível encontrarmos aspectos descritos como oriundos da depressão nas manifestações melancólicas no transtorno bipolar. Então, quando nos referirmos à melancolia estaremos falando da assim chamada fase depressiva descrita em termos psiquiátricos atuais.

Além desta diferenciação, é importante destacarmos a experiência da depressividade, descrita como aquela que apreende a tristeza como modo de ser global do depressivo em encontro consigo, com o mundo e com o outro. O conceito de depressividade é trazido por Tatossian (1979/2006) como hipótese, se definindo sobre e na experiência como movimento próprio do sujeito, unindo passividade e atividade, receptividade e espontaneidade. Uma reflexão empreendida cotidianamente, fruto substancial daquilo trazido pela psicopatologia fenomenológica (Tatossian, 1979/2006). Esta conceituação condiz fielmente com os paradigmas da psicopatologia fenomenológica, construindo descritivamente um modo de o sujeito existir em movimento, dinâmico e capaz de se ressignificar na experiência e pela experiência.

Percebemos que a melancolia, a depressão e a experiência da depressividade possuem aspectos em comum e não podemos, de forma rígida, delimitar tais manifestações, principalmente diante da diversidade das manifestações humanas. A tristeza claramente atravessa tais experiências e, na atualidade, não encontramos uma distinção entre uma e outra manifestação; fala-se apenas em depressão. No entanto, 
neste artigo optamos por manter o termo melancolia por ser o termo utilizado por autores como Tatossian (1979/2006) e Binswanger (1960/2005).

\section{Melancolia}

A melancolia é um distúrbio da ordem do humor, o que permite ao menos uma estabilidade relativa, pois cria um traço de passividade, subtraindo a vontade do sujeito. Este humor se enraíza na totalidade do sujeito, não aquela da pessoa individual, pois nele há um traço de a historicidade que impossibilita a inserção na lógica de ações/reação próprias da biografia do sujeito (Tatossian, 1979/2006).

O humor é, segundo Tatossian (1979/2006), uma má tradução da palavra alemã Stimmung, pois vai além da contingência do humor como relação com o ambiente, estando mais presente, segundo Minkowski (1933/1995), como categoria fundamental do vivido, do sentir, do viver - chamada por ele de afetividade-contato e também traduzida como sintonia, ressonância. Ele cria um fundo global único a cada momento, depreendendo-se da esfera vital do ser humano e se enraizando na sua totalidade, dando-lhe uma "profundidade" não cronológica. Há uma alteração do humor relativa a um distúrbio do tempo vivido, gerador da melancolia (Tatossian, 1979/2006).

Na melancolia há sim uma questão afetiva, no entanto, ela é diferente de um sentimento, pois está dissociada de um tempo biográfico. Tatossian (1979/2006) coloca que a psicose maníaco-depressiva, bem como a esquizofrenia, são perturbações qualitativas da sintonia, ou seja, não há uma sintonia com aquilo que está realmente acontecendo. O contato com a realidade é modificado, não há um objeto que o faz sofrer; é um "sofrimento anormal, pervertido, deformado" (Tatossian, 1979/2006, p. 117). A tristeza é metafórica, uma tentativa de exprimir a si mesmo e ao outro aquilo situado na ordem do inexprimível ou mesmo inexplicável - um sentimento de vazio, de petrificação, de não-viver. Ela é desprovida de movimento, sem desencadeamento; o Eu assiste como espectador a distimia (Tatossian, 1979/2006).

Na tradição da psicopatologia fenomenológica, desde 1920 diversos autores como Minkowski, Strauss e Von Gebsattel atribuem à alteração do tempo vivido um status de elemento fundamental da melancolia. Tal alteração provoca uma diminuição e estagnação do tempo íntimo, imanente ao sujeito. Trata-se de uma unidade fenomenológica além do campo causal, situado na essência do fenômeno. O sujeito não é mais regido pelo futuro em que o vivido se perderia e perde sua sincronia com o tempo do mundo. A estagnação do tempo retira a categoria do possível como capacidade, há uma despotencialização. Ser melancólico é

fundamentalmente não-poder comer, pensar, compreender, trabalhar, fazer amor, mas é também registrar cruelmente esta incapacidade e portanto também sempre ensaiar agir, lutar contra o inacabamento obrigatório das ações. As capacidades técnicas da utilização racional do objeto estão certamente disponiveis ao doente, mas sua ação lhe permanece estranha (Tatossian, 1979/2006, p. 128).
A melancolia é situada como uma inibição do devir e como uma estagnação do tempo. O sujeito busca sua salvação em um esforço vão de mudar o passado. Há um passado que não pode se dissipar e se faz sempre mais pesado e determinante, algo além de um simplismo de uma substituição do presente e futuro pelo passado. Não é um passado do homem normal, pois este passado perdeu toda significação, toda a historicidade, mas não deixa de se impor ao melancólico. A temporalidade melancólica, por estar fora de toda duração, é pura cronologia. O peso do passado se manifesta como uma falta inapagável da progressão do futuro. Há uma dívida com o devir, o não-poder, a incapacidade de ação. A culpabilidade normal não é possível, pois ela supõe uma estrutura temporal desaparecida no melancólico (Tatossian, 1979/2006).

A angústia melancólica é marcada pelo não-poder ser, não-poder viver; uma impotência diante da vida. Tal impotência modifica suas relações com a morte, podendo torná-la mais familiar, desejada e vivenciada como liberação, oriunda de uma pressão do vivido altamente elementar. Como não há ressonância pessoal e o tempo é vazio, não há nada entre o instante presente e a morte e na sua presença ele vive constantemente. É uma morte transcendente que angustia o melancólico, exterior a ele, permitindo ser o objeto do medo, mas também de seu desejo e impulsos suicidas. Uma espécie de justaposição de desejos incompatíveis; um desejo de morte imanente que é desejo de vida - uma dualidade insuperável e tal projeto suicida jamais pode ser autenticamente realizado, pois a morte efetiva é justamente seu fracasso (Tatossian, 1979/2006).

$\mathrm{Na}$ compreensão de seu si-mesmo, o sujeito fica inteiramente restrito aos papéis sociais, distanciando-se de uma existência autêntica (Bin, 1998). A despotencialização provocada pela melancolia permite delinear o comum ideário suicida do melancólico, pois somente assim estaria saindo de uma desesperança, de uma passividade instaurada; o sujeito passaria a ser autor de sua própria existência.

O melancólico, para Bin (1998), possui uma atitude denominada por ele de post festum; como se o futuro e o presente estivessem presos ao passado, não havendo possibilidade de atualização - "uma fixação pronunciada sobre suas experiências já adquiridas" (Bin, 1998, p. 28). Para o melancólico, o imediatismo é extremamente estranho e doloroso, pois está preso de forma passiva ao seu passado.

Binswanger (1960/2005) não reconhece nenhuma diferença entre a melancolia reacional e a melancolia endógena, pois na medida em que a melancolia reacional responde a critérios clínicos da melancolia, é para ele uma melancolia endógena, uma fase do transtorno bipolar. Para ele, sem a circunstância a doença não se manifestaria nesse momento e, se não existisse uma questão constitutiva, o sujeito, mesmo com a circunstância, se manteria em uma boa saúde. Ou seja, seu sofrimento não está dissociado dos acontecimentos da sua vida, mas, ao mesmo tempo, não podem ser considerados como desencadeadores únicos.

Para Binswanger (1960/2005), os melancólicos se colam ao passado, não conseguem se desatar do passado e são inteiramente dominados por ele. Em relação ao futuro, não veem nenhum futuro diante deles e o presente não significa nada, é vazio. Trata-se de uma perda da protensão melancólica que se estende a todos os domínios da vida. Na melancolia, 
a estrutura da constituição intencional do tempo pode estar tão alterada, tão defeituosa, que pode não aparecer nenhum propósito de vida, gerando uma angústia correspondente pela ausência de um objeto. É possível falar de dois modos de angústia, uma pela melancolia ligada a um objeto e outra de um sofrimento sem objeto (Binswanger, 1960/2005).

A autoreprovação melancólica é uma das características do mundo melancólico, atravessado por vários "Se". O sujeito fica colado ao passado, pensando em possibilidades vazias de mudança de um passado que não contém possibilidades. A retenção se confunde com a protensão e não se desdobra em um propósito autêntico, mas somente em uma discussão vazia, que não leva a lugar nenhum (Binswanger, 1960/2005).

Para Binswanger (1960/2005), isto é um sinal que, com a alteração da protensão, além da alteração do processo inteiro do fluxo e da continuidade da temporalização, o pensamento, em geral, também é alterado. Deste ponto de vista, em termos psiquiátricos, por alterar também o pensamento, a melancolia pode ser colocada como uma doença ainda mais grave, uma alteração bem mais profunda, indo além ao que o autor suporia do ponto de vista de uma curabilidade. Para ele, o fundamental na melancolia não é o humor triste ou mesmo a tristeza, mas a despotencialização emocional e intencional do sujeito.

$\mathrm{Na}$ prospecção melancólica o doente também apresenta o futuro como perda e a felicidade é posta no campo da impossibilidade. Tatossian (1979/2006) compreende que interpretar tal manifestação como pessimismo exacerbado seria inadequado. Não há presunção de perda, já que não há possibilidade aberta e a experiência melancólica é reduzida a poucas possibilidades, mas que também é poderosa por apresentar uma evidência inabalável. Dessa forma, tanto a retrospecção quanto a prospecção melancólica revelam um relaxamento da estrutura intencional das objetividades temporais, mas também uma retessitura em que retenção e protensão infiltram-se mutuamente.

\section{Mania}

A fenomenologia, em suas teorizações sobre o tempo vivido, não tem demonstrado muito interesse pela mania, muito pelo fato de não ser uma síndrome "pura" e seu "segredo" estar situado na melancolia. No entanto, a manifestação maníaca é tão curiosa que há uma dificuldade em situá-la na região do ser humano em termos de psicopatologia do homem normal (Tatossian, 1979/2006).

Para compreendermos a mania, necessariamente devemos ir até o tempo vivido. O maníaco vive numa série de presenças isoladas de instante a instante, explodindo sua biografia e a reduzindo a um presente com destaque em relação ao passado e ao futuro (Binswanger, 1960/2005; Tatossian, 1979/2006, 1997). Segundo Minkowski (1929/2002), o maníaco excitado não consegue estabelecer em suas relações com o meio, uma duração, não constitui um presente. Seu contato com o ambiente é reduzido unicamente ao agora sem haver mais presente, respondendo avidamente aos apelos de fora (Minkowski, 1929/2002; Tatossian, 1979/2006). Dessa forma, o maníaco consome seu ambiente, "o suga até o sangue" (Binswanger, 1960/2005, p. 86) de tal forma que é capaz de levá-lo à ruína ou destruí-lo.

Segundo Tatossian (1979/2006), tanto na melancolia quanto na mania "o motor é o relaxamento intencional da temporalidade" (Tatossian, 1979/2006, p. 166). Vive-se em uma pura apresentação, sem protensão ou representação, em puros "presentes" privados de retenções e que, embora se constituam em um mundo intersubjetivo, dificilmente podem constituir um mundo comum. Então, para Binswanger (1960/2005), trata-se da análise da falha da apresentação na mania e da impossibilidade da constituição de um mundo comum.

Falta um desdobramento no tempo, o paciente na fase maníaca vive demasiadamente o agora e é neste agora que delimita seu contato com o ambiente. Este contato com o mundo, bem como o do melancólico, também é deficiente, pois está reduzido a um presente inautêntico e impessoal. Ele vive em um mundo falso, aparentemente rico, mas de fato empobrecido sob uma máscara que esconde uma solidão ampla (Tatossian, 1979/2006). Ele vive de instante em instante e não vive mais que esse instante em uma espontaneidade excessiva, esquecendo o passado e sem pensar no futuro, constituindo-se amplamente no presente como um horizonte protentivo ilimitado (Binswanger, 1960/2005, p. 84).

Seu sintoma clássico e fio condutor é a fuga de ideias, evidenciado qualitativamente por Binswanger como forma de ser-no-mundo. Sua relação com o outro tem como característica não distinguir socialmente o outro, marcando tal relação por um "otimismo do humor" gerador de luminosidade, alegria, fugacidade e rapidez (Tatossian, 1979/2006). O outro passa a ser evidenciado de forma positiva e impessoal, sem reconhecer nele suas características sociais, ou seja, ele vive em um mundo atolado na contingência do presente e que não reconhece qualitativamente o outro, escondendo sua solidão por uma fuga de ideias anteriores.

O outro não se constitui como um Alterego, mas sim como um estrangeiro em uma contínua desvalorização do outro, uma experiência de coisa ao invés de uma experiência de outro (Binswanger, 1960/2005). Então, não é a história de vida, a biografia, nem uma série de retenções ou horizonte de protensões que motiva suas ações. Ele é levado por uma ideia puramente presente, situada de fora do contexto biográfico, sem determinantes temporais, capaz de transformar sua organização doméstica em um caos. Suas protensões são vazias, sem sentido justamente pela ausência retencional; ocorre uma ideia sem significação, puramente momentânea por não ter nenhuma motivação na constituição temporal. Então, a alteração na estrutura da objetividade temporal na mania se apresenta em duas direções. Por um lado pela falta da continuidade de um sentido e do curso do pensamento, e por outro lado pela falta de continuidade da apresentação em seu ancoramento biográfico habitual (Binswanger, 1960/2005).

No mundo maníaco não há diferenciação, mais ou menos densidade, opacidade, resistência; ele vive uma total contingência, abrindo caminho para a influência exacerbada de coisas e pessoas encontradas. Ele é, no mais alto grau, sujeito à influência, à sugestão do outro por não passar de pura volatilidade e fugacidade (Tatossian, 1997, 1997/2006).

O maníaco é puro presente, porque 
não encontra "defesa" num passado sólido e num futuro efetivamente projetado, que ele é o que mundo (material) faz dele, que ele é esse mundo. Entregue a um presente inautêntico porque descentrado da estrutura global do tempo pessoal, o ser maníaco é existência lúdica ou, se se quer evitar a apreciação moral que implica a noção de eu, ele é festa, festa da Presença, festa fora do tempo e do espaço sério da vida propriamente pessoal. Mas como em toda festa, a morte se esconde sob a exaltação da vida e, aqui, o ser-no-mundo melancólico sob o ser-no-mundo maníaco (Tatossian, 1979/2006, p. 149-150).

Esta pureza de momento não se prende a um caráter puramente maníaco, pois talvez o mais denso, o estofo, o problemático de seu mundo esteja naquilo que está por trás, a melancolia, e nos dá abertura para pensarmos na bipolaridade.

\section{Tempo vivido bipolar: duas formas de existir no mundo}

Binswanger (1960/2005) opõe de forma interessante os "mundos do humor" maníaco e melancólico. Segundo ele, quando

alguém ou algo signifique aqui Deus, lá o diabo, aqui bom, lá mau, aqui branco, ali preto, aqui alegria, ali tortura, não forma mais que o acme mais surpreendente desta antinomia. No fundo, ela se estende no espaço e no tempo, no ritmo, na consistência e na coloração, na luz e no movimento da existência. Se na forma de existência maníaca o espaço se alarga e torna-se infinito, aqui eles saem justamente do "espaço" num distante inatingível; lá o tempo se encurta, aqui ele se alonga; lá o ritmo do vivido é rápido, aqui é lento; lá o Mundo é volátil (fugaz, ligeiro, ágil), rosa e claro, aqui ele é resistente, pesado e duro, negro e sombrio (Binswanger, 1960/2005, p. 113-114).

Para Binswanger (1960/2005), existem diferenças constitutivas que residem na falha da constituição temporal. Na mania, pelo relaxamento da estrutura temporal do mundo próprio ou primordial do ego, a estruturação de um mundo comum fica comprometida e a vida do sujeito fica pautada em uma pura atualidade. Na melancolia, vive-se em um passado ou em um futuro alterado, tendo como conseqüência a ausência de perspectiva de presente. Existem diferenças evidenciadas em diferentes intensidades, mas que não nos permite falar, segundo Binswanger (1960/2005), em uma antinomia. São modos de constituição da consciência humana e que, no caso do Transtorno Bipolar, estabelecem uma relação circular.

Martins (2003) resume as ideias de Binswanger sobre este tema afirmando que o melancólico e o maníaco vivem em um presente eterno. Na melancolia, sem se livrar do peso e da dor da existência, sem fluir numa temporalidade própria do humano. Na mania, um sujeito que se lança sempre aberto a possibilidades futuras, perdendo a capacidade retentiva e sem constituir-se historicamente - uma protensão desordenada.

A perspectiva trazida por Binswanger representa uma importante contribuição à clínica fenomenológica no sentido de buscar os momentos estruturais do mundo melancólico e do mundo maníaco. Há uma tentativa de compreender em que momento há uma falha estrutural que permite cons- tituir a melancolia e a mania e fica evidente que tal falha está relacionada à questão da temporalidade. Não há um desdobramento no tempo, o sujeito sofre por não conseguir vivenciar o tempo já que a ligação entre passado, presente e futuro está comprometida. No transtorno bipolar, caracterizado justamente pela oscilação não linear entre estas duas fases clínicas, a complexidade é ainda maior por se tratar de formas de funcionamento aparentemente opostas, mas que possuem uma forte ligação, podendo uma fase dizer muito sobre a outra.

Todas as descrições estruturadas por nós daquilo que seria o mundo melancólico e maníaco nos permitem delinear as manifestações psicopatológicas da bipolaridade. Não se trata de uma simples associação entre uma fase e outra - "a lentificação depressiva que vira excitação maníaca, mas a tristeza permanece" (Widlöcher, 1995/2001, p. 32). Este é um ponto fundamental que perpetua o mundo vivido bipolar e é muitas vezes deixado de lado. Há um fundo mental, como diria Minkowski, por detrás de tais fenômenos psicopatológicos e formas de ser-no-mundo que devem ser compreendidos.

\section{Considerações finais}

Empreender uma compreensão fenomenológica acerca de quadro psicopatológico significa uma tentativa de compreender o mundo vivido do sujeito, seu modo de ser global através de elementos constitutivos como a temporalidade, a espacialidade e a corporeidade. Neste artigo, a ênfase foi a temporalidade como elemento constitutivo fundamental da bipolaridade.

Diferentemente de concepções tradicionais de psicopatologia que enfatizam a doença e o diagnóstico ou mesmo de uma psicopatologia somente descritiva, a psicopatologia fenomenológica defende o abandono da atitude natural, a recusa de prejulgamentos, buscando sempre trabalhar em fluxo através do constante contato com o paciente e com a experiência vivida patológica.

Binswanger, considerado um dos fundadores da psicopatologia fenomenológica, desenvolve em suas últimas obras uma compreensão genética que busca a origem da melancolia e da mania e situa o transtorno bipolar como oriundo de uma falha na constituição temporal do sujeito. Esta compreensão genética está no centro do processo de desenvolvimento da psicopatologia fenomenológica, saindo de um modelo somente descritivo para um modelo também constitutivo, que tem como objetivo desvelar os processos constitutivos das doenças mentais.

Tatossian, por sua vez, enfatiza um modelo de psicopatologia fenomenológica que se sustenta sempre no encontro entre psiquiatra e paciente, buscando compreender as experiências humanas em sua cotidianidade. Trata-se de um olhar para a psicopatologia que se distancia de um modelo inferencial, pautado em manuais e referências anteriores, e busca apreender os modos de ser global do sujeito, indo além de uma concepção pautada puramente nos sintomas e tendo como característica a crença na potencialidade do sujeito e na possibilidade de crescimento.

Embora existam elementos particulares nas concepções do transtorno bipolar trabalhadas neste artigo, a tempora- 
lidade é o principal elemento de análise e compreensão. O sofrimento bipolar é atravessado pela questão do tempo, seja por uma estagnação do tempo em que o passado é o que rege a vida, seja por um agora demasiado, eufórico e desfocado.

$\mathrm{Na}$ fase melancólica, podemos dizer que o bipolar parece parar no tempo, enquanto na fase maníaca parece "dançar" sem se preocupar com quem conduz sua dança. Didaticamente parece simples separarmos duas dimensões que, na verdade, compõem um mesmo mundo vivido. Mas estas dimensões são, de fato, inseparáveis. Mania e melancolia se constituem mutuamente no mundo vivido. A oscilação, aparentemente paradoxal, é o que torna a bipolaridade tão enigmática e ao mesmo tempo demasiadamente humana.

\section{Referências}

Alcantara, I., Schmitt, R., Schwartzthaupt, A. W., Chachamovich, E., Sulzbach, M. F. V., Padilha, R. T. de L., Candiago, R. H., \& Lucas, R. M. (2003). Avanços no diagnóstico do transtorno do humor bipolar [Versão Eletrônica]. Revista psiquiatr. Rio Gd. Sul, 25(1), 22-32.

American Psychiatric Association (2002). Manual diagnóstico e estatístico de transtornos mentais - DSM - IV ( $4^{\mathrm{a}}$ ed. rev.). Porto Alegre: Artmed.

Bin, K. (1998). Fenomenologia da depressão estado-limite. Revista Latinoamericana de psicopatologia fundamental, 1(3), 11-32.

Binswanger, L. (2005). Melancolie et Manie. Paris: Presses Universitaires de France. (Trabalho original publicado em 1960)

Goodwin, F. K., \& Jamison, K. R. (2010). Doença maníacodepressiva: transtorno bipolar e depressão recorrente $\left(2^{\mathrm{a}} \mathrm{Ed}\right)$. São Paulo: Artmed.

Lima, M. S., Tassi, J. L., Novo, I. P., \& Mari, J. J. (2005). Epidemiologia do transtorno bipolar [Versão Eletrônica]. Rev. psiquiatr. clín., São Paulo, 32(15), 15-20.

Magalhães, P. V. S., \& Pinheiro, R. T. (2009). Epidemiologia do Transtorno Bipolar. In F. Kapczinski \& J. Quevedo (Eds.), Transtorno Bipolar: Teoria e Clínica (pp. 17-27). São Paulo: Artmed.

Martins, F. (2003). Psicopathologia II: Semiologia Clínica: Investigação Teórica Clínica das Síndromes Psicopatológicas Clássicas. Brasília: Universidade de Brasília, Instituto de Psicologia.

Minkowski, E. (1995). Le temps vecu. Paris: Presses Universitaires de France. (Trabalho original publicado em 1933)
Minkowski, E. (2002). A noção do tempo em psicopatologia. Revista da Associação Psicanalítica de Porto Alegre-Clínica da adolescência, 23, 109-126 (Trabalho original publicado em 1929)

Moreira, V. (2001). Más allá de la persona: Hacia una psicoterapia fenomenológica mundana. Santiago: Universidad de Santiago de Chile.

Moreira, V. (2002). Psicopatologia crítica. In V. Moreira \& T. Sloan, (Eds.), Personalidade, Ideologia e Psicopatologia Crítica (pp. 109-248). São Paulo: Escuta.

Moreira, V. (2009). Clínica Humanista-Fenomenológica: estudos em psicoterapia e psicopatologia crítica. São Paulo: Annablume.

Organização Mundial de Saúde - OMS (1993). Classificação de transtornos mentais e de comportamento da CID - 10: descrições clínicas e diretrizes diagnósticas. Trad. Dorgival Caetano. Porto Alegre: Artes Médicas.

Silva, J. L., \& Cordás, T. A. (2006). Transtorno Bipolar do Humor. In C. N. de Abreu \& cols. (Eds.), Síndromes psiquiátricas: diagnóstico e entrevista para profissionais de saúde mental (pp. 47-54). Porto Alegre: Artmed.

Strauss, E. (2000). Uma perspectiva existencial do tempo (J. N. G. de Araújo, Trad.). Revista Latinoamericana de Psicopatologia Fundamental, 3(3), 115-123. (Trabalho original publicado em 1968)

Tatossian, A. (1997). Psychiatrie phénomenologique. Paris: Acanthe.

Tatossian, A. (2006). A fenomenologia das psicoses (J. C. Freire \& V. Moreira, Trads.). São Paulo: Escuta. (Trabalho original publicado em 1979)

Thobaben, M., \& Wehr, S. (2004). Bipolar Disorder: Manic Episode [Versão Eletrônica]. Home Health Care Management Practice, 16(300), 300-301.

Tung, T. C. (2007). Enigma bipolar: conseqüências, diagnóstico e tratamento do transtorno bipolar. São Paulo: MG Editores.

Widlöcher, D. (2001). As lógicas da depressão. Lisboa: CLIMEPSI. (Trabalho original publicado em 1995)

Recebido em 09.08.2010

Primeira decisão editorial em 28.01.2011

Versão final em 01.04.2011

Aceito em 23.07.2012 